\title{
Implementation of an Expert System for Automated Symptom Consultation in Perú
}

\author{
Gilson Vasquez Torres, Luis Lunarejo Aponte, Laberiano Andrade-Arenas \\ Facultad de Ciencias e Ingeniería \\ Universidad de Ciencias y Humanidades \\ Lima, Perú
}

\begin{abstract}
The human being has a fragile life, and is attacked by different diseases throughout his life, neglecting or ignoring some of them because it is considered minimal, can be fatal, but many do not want to attend a health center, so they seek your symptoms on the Internet and finding pages with false information, that is the problem that we will address in this investigation. The objective of the research is to implement an expert system, creating a web page that provides real information when a user enters their symptoms. This was achieved based on the logic of rules developed in Prolog, so when a user fills out the created questionnaire, the expert system will follow. the rules to conclude with the desired diagnosis; all these steps were carried out using the buchanan methodology. The result was an improvement in the accessibility of truthful information through the Internet, facilitating the management of appointments of users if they have a serious illness, or the treatment in case of a minor illness. The beneficiaries of the research were the population that required the use of the automated query application.
\end{abstract}

Keywords-Automated query; buchanan; expert system; prolog; symptoms

\section{INTRODUCTION}

Since the end of 2019, there is no person who has not been affected by the pandemic experienced, every area of life itself was changed in many ways, the general population is in a state of constant alarm and concern as to whether they are sick from COVID-19 or not [1].

Globally, there were waves of excessive contagions, which brought high peaks of death, in addition, very few people considered that the COVID-19 is not the only disease in recent years, even in the midst of the pandemic, people were struggling with other diseases, from the simplest [2] , such as the common flu, to the strongest and deadliest, such as cancer.

It is for all this that millions of individuals in Peru and the world resort to the use of the Internet to learn about their illness, by entering their symptoms in the search engine of their choice, in order to get immediate help, and in most cases, proceed to self-medication to avoid the cost of medical appointments or time spent in the hospital [3].

Many times when resorting to unreliable sites, people are exposed to receive information that can be harmful to them, since many of these diagnoses are written by bloggers or people who did not have a higher education and who do not have the appropriate knowledge to derive a clinical solution [4].

The main objective is the creation and implementation of a system through a web page with accurate information, this would be achieved by affiliating doctors as editors, in addition to having a relationship with a nearby medical center for prompt attention [5] [6]. The aim is to classify the patient's level of need for care, whether he/she can be treated using telemedicine or referred to a face-to-face appointment .

To achieve the best selection for the benefit of the user, at the time of putting their symptoms, is through an expert system, which is a branch of artificial intelligence [7], that allows decision making based on a set of rules, so when a patient indicates their ailment, the system will select the diagnosis with more matches [8].

The resulting benefits are the clearest, both for the person himself, because at last, he will have a place where he can have a solution to his health problem and that it is also reliable and, on the other hand, it is very beneficial for the network of hospitals and clinics affiliated to the website [9], because they will have a greater number of patients .

On the other hand, another of the great benefits that we obtain by applying directly on a web page, is the direct interaction with the user. Peru is a country with a large sector of poverty, not everyone can buy expensive devices for downloading mobile applications, but websites are more accessible to all Peruvian citizens [10]. At a general level, there is a need to modernize the prompt care of the population, especially in a health crisis, such as a pandemic.

The paper is structured as follows: in Section II, the literature review; in Section III, the methodology, where the steps to be carried out are indicated; in Section IV the results and discussions; finally in Section V the conclusion and future work.

\section{Literature REVIEW}

The research principle allows the visualization in a global way, how expanded and well executed the digital format related to the health area is, speaking specifically about the search for symptoms and treatments for non-lethal situations, in the current context of the pandemic. The number of searches on websites has multiplied, to know for sure if the symptoms suffered by a person could be a serious illness, but when doing this search for symptoms on the Internet we are faced with a main problem, of finding a sea of pages with erroneous or unverified content.

With respect the subject of study, research shows the great growth of internet searches on health issues, being this way that [11] Jozsef in its research on Health Information on the 
Internet, tells us that research has revealed that more and more Internet users are accessing health-related websites to search for health information and are relying on it to answer their health questions. Therefore, in the following study [12] it is confirmed that Internet searches can help people find not only the symptoms of the disease, but also various treatment options, this information is largely hosted in social media communities such as blogs, social networks, e-mails, among others [13].

Based on this, it is known that there is a need for the population to understand the medical situation they are going through, Macrohon in a study on real-time COVID-19 data visualization and information [3] reveals that studies have shown that people of all age groups search the Internet for information about their health, illnesses, care and treatment, in addition, a great variety of texts, images, graphics, files and audio and video applications that are uploaded on different websites, supported by the poor knowledge of people on health issues, affects people's search for information, since this information is of low quality and from not very credible sources.

Knowing that most of the health information found on the internet is not very reliable [12] Waltters in a study on virtual clinic care in these pandemic times, I affirm that the websites and health-related information on the internet show inconsistent quality with incorrect data and unreliable sources, the medical community has therefore begun to question the reliability of using websites to search for information.

For this reason [11] indicates that professionals who are in charge of developing websites to provide health services with respect to people's health, focusing on the needs of the users, this help is necessary to eliminate any health ignorance.

On the other hand, in the following study on the adaptation of an expert system for medical diagnosis [14] it was found that at present most websites are not properly prepared to provide health information. Many of the sites studied violated the basic guidelines for remote access, whether mobile or web, and nongovernmental sites have proven to be in a better position to adapt to the new needs of patients. This is, a limitation of cyber resources for the population, so the state or government web pages related to health must adapt to the new changes quickly in order to meet the needs of the population.

To put the situation of the websites in order, author Muhammand in his research on web-based clinic management system compared by scores the level of information of the websites [15] These showed us that the level of help provided is directly referential to the type of search, which means that there are searches that will be helpful and useful, such as searching for beneficial help on websites, but a lower percentage of useful information and help on personal help sites [16].

Reviewing other research can see that in addition to being able to score the various health sites, they were also rated by percentage of truthfulness, as in the following study on user participation in health websites, [17] shows a worrying result, $87.2 \%$ of the pages that have been examined are not verified and do not have official code certificates, which could result in false information about the current health crisis in the world. Entities should improve their satellite education dissemination system as soon as possible, which would make more people literate in the area of health and personal care.

Finally, must be clear that the population is looking for a lot of information on health food care, [18] this recent study revealed that websites in Europe do not have good information quality despite having unique criteria patterns. It should be noted that only half of the websites had correct information.

In addition, the following research on the digital inclusion of health information websites [18] tells us that none of the websites found in this study had nutritional advice that met the quality criteria $100 \%$. In conclusion, several works have been analyzed, including scientific articles and theses. Objective to implement an expert system for automatic symptom queries.

Applying an expert system in the healthcare area is an important step in obtaining reliable medical diagnoses. At this time, people are putting their physical and mental health at risk by consulting symptoms of any kind on the Internet. What intend with this research is to establish a reliable source for anyone who wants quick help. Any person would only have to go online, enter their symptoms and the system would automatically determine what these people suffer from, helping a lot to make decisions, to go to a medical center or buy basic medicines that do not require a prescription.

\section{Methodology}

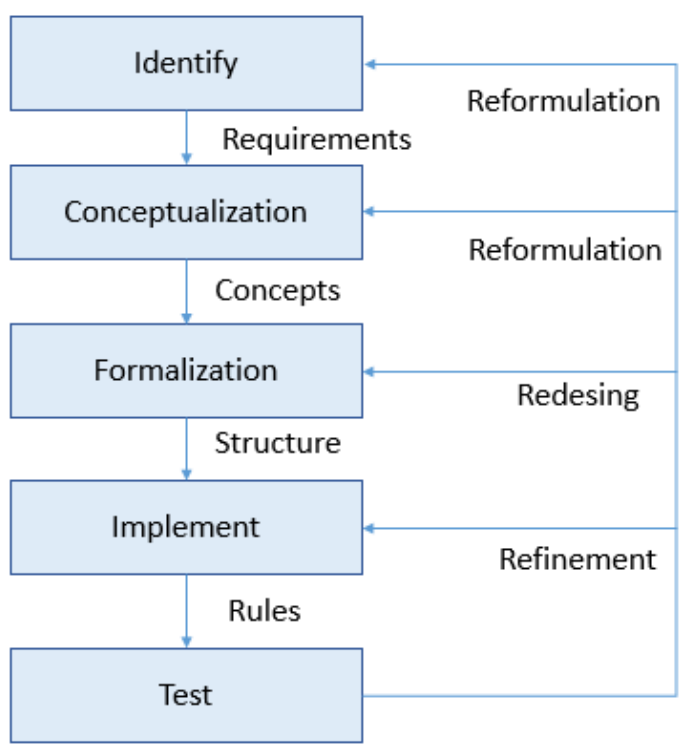

Fig. 1. Methodology Buchanan.

\section{A. Stages of the Methodology}

For the development of the expert system was used the BUCHANAN methodology shown in Fig.1. Which is a methodology based on the cascade life cycle that was used in the beginnings of software engineering, with this it is deduced that the process of construction or development of the expert 
system will be carried out with a process of almost constant revision since this methodology follows the software (expert system) in its different phases [19], which make a hierarchical life cycle; these are defined in 6 modules.

1) Identification: In this step the participants, roles, actors to build the system and their functions in the construction are identified. At this stage, the available resources and sources of knowledge are also identified, as well as the objectives or goals of the expert system.

2) Conceptualization: The knowledge of the field expert is described, knowledge obtained for the project, in order to delimit the system, this to identify and characterize the problem, the scope of the expert system is defined, this means that the specific problems to be solved by the expert system must be specified.

3) Formalization: The structure of the expert system is obtained, and with the problem well defined, was begin to identify what is required to be done in the different functions or tasks to be solved by the expert system, relevant and important concepts are identified, as well as the result of formalizing the conceptual information diagram the Bayesian network, which will be used to identify the rules of the expert system, at this stage of the methodology, the specifications are defined to first build the prototype of the knowledge base.

4) Implementation: This step begins with the development of the expert system, based on the data previously obtained, such as the identification of the study variables, the tasks of the expert system, the use cases, the Bayesian Network, the rules, among others, then the programming language will be chosen,the programming environment, which is the choice of the set of programs for the realization of the project and finally the general organization of the development, all this allows an adequate creation of the knowledge base of the expert system and of the prototype to be tested in the following step [20].

5) Test: Having the prototype, observe the behavior it has during its execution, and the key points that analyze are, the operation of the knowledge base, that is, how it reacts to the information it processes within the system and the second point is the structure of inferences, which is the response it has in the interaction.

\section{B. Methodology Development}

\section{1) Identification:}

- Problem:

Currently, there is no website adequate to the needs of people who search for their symptoms on the Internet, and even less, an expert system that can provide a reliable basic diagnosis for the user to make health care decisions.

- Solution:

Propose the creation of a rule-based expert system with the utility to provide basic diagnostics for a virtual triage process, thus streamlining existing medical consultations.

- Familiarization with the Domain:

In order to carry out the familiarization and mastery, the face-to-face triage process was studied with all

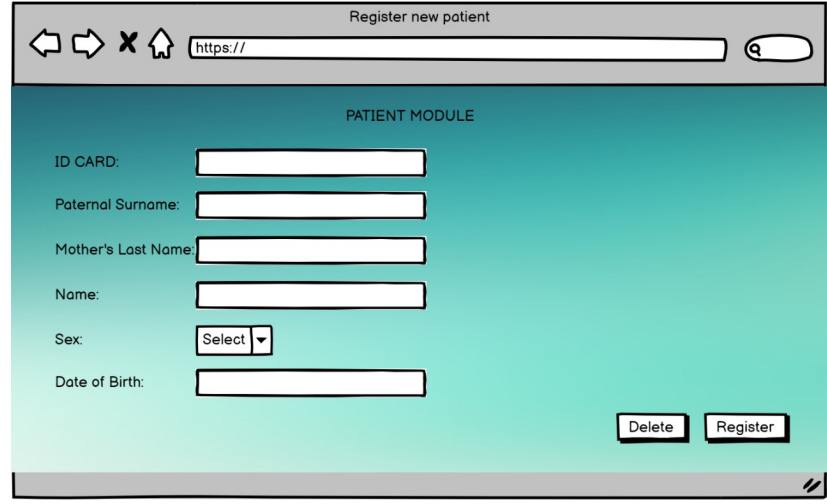

Fig. 2. Patient Registration Module.

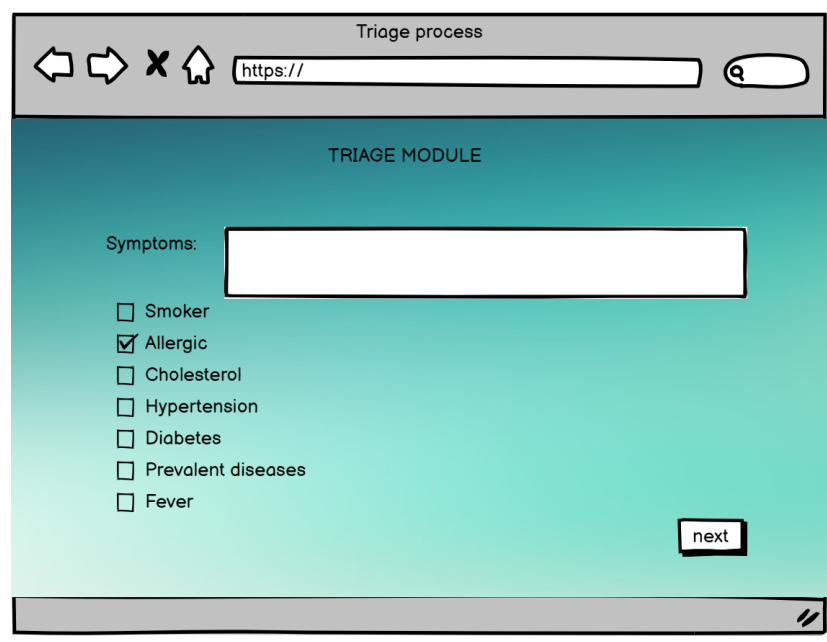

Fig. 3. Triage Module

the corresponding procedures. Once the problems and domains have been identified, continue with the development of the expert system tasks.

- $\quad$ Expert System Tasks

- Enable to register patients to the system, this module is shown in the Fig. 2.

- Allows triage from home, a module shown on the Fig. 3.

- To allow through a module the learning of the expert system, in order to continue expanding the knowledge base.

- Allow the system to diagnose possible disease based on the patient's symptoms, diagnosis module.

- Enable the system to display the results of the diagnostic, as shown in the Fig. 4.

2) Conceptualization: In this stage of the methodology, proceeded to obtain the knowledge of the expert system, qualitative information was needed for the research, this to be able to apply it in the rule-based model to be used, from the different models that can be applied for decision-based structures, the Bayesian network was chosen, to be able to use this model and implement it in the expert system for the creation of the knowledge base, the target variable was 


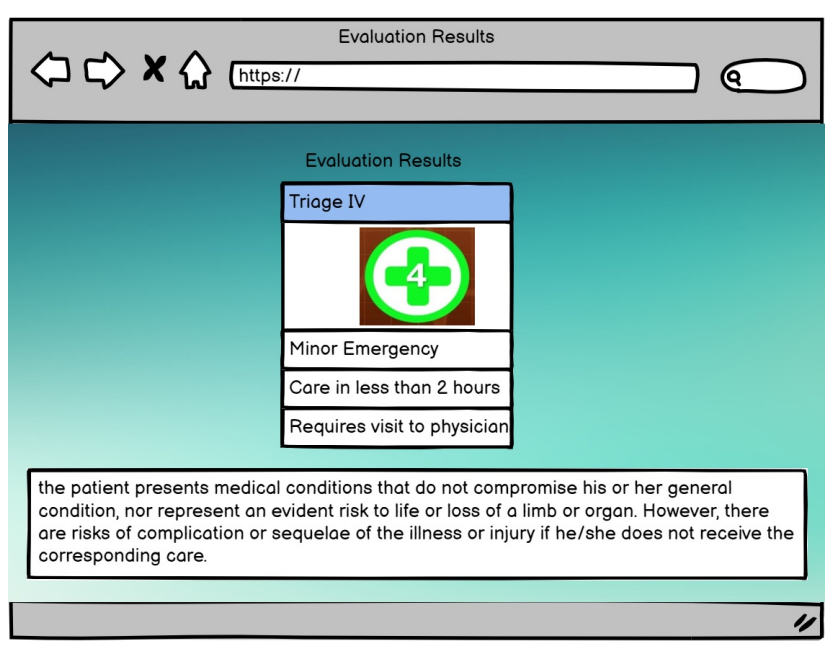

Fig. 4. Result Module.

identified as shown in Table I, as well as the observation variables that are specified in Table II, once these 2 variables were identified, the knowledge base will be created.

- Target Variable: As shown in Table I.

TABLE I. IDENTIFICATION OF THE TARGET VARIABLE

\begin{tabular}{|l|l|l|}
\hline Description & \multicolumn{1}{|c|}{ Variable } & \multicolumn{1}{c|}{ Range } \\
\hline $\begin{array}{l}\text { Symptom consulta- } \\
\text { tion }\end{array}$ & Triage Priority(PT) & $\begin{array}{l}\text { Triage I, Triage } \\
\text { II,Triage III, Triage } \\
\text { IV, Triage V }\end{array}$ \\
\hline
\end{tabular}

- Observation Variables: As shown in Table II.

TABLE II. IDENTIFICATION OF OBSERVATION VARIABLES

\begin{tabular}{|l|l|l|l|}
\hline Nro & \multicolumn{1}{|c|}{ Description } & Variable & \multicolumn{1}{c|}{ Range } \\
\hline 1 & Age & ED & Under Age, Adult \\
\hline 2 & Can walk & CA & Yes, No \\
\hline 3 & Over Weight & SP & Yes, No \\
\hline 4 & Allergy & AL & Yes, No \\
\hline 5 & Smoke Cigarettes & FU & Yes, No \\
\hline 6 & Cholesterol & CO & Yes, No \\
\hline 7 & Can Speak & HA & Yes, No \\
\hline 8 & Fever & FI & Yes, No \\
\hline 9 & Muscle pains & DM & Yes, No \\
\hline 10 & Hypertension & HI & Yes, No \\
\hline 11 & You can obey simple orders & OB & Yes, No \\
\hline 12 & Diabetes & DI & Yes, No \\
\hline 13 & Prevalent Diseases & EP & Yes, No \\
\hline 14 & High pressure & PA & Yes, No \\
\hline 15 & Can Breathe & RE & Yes, No \\
\hline 16 & Dizziness & MA & Yes, No \\
\hline 17 & Nausea & NA & Yes, No \\
\hline 18 & Loss of Memory & PM & Yes, No \\
\hline 19 & Blurred Vision & VB & Yes, No \\
\hline 20 & Vital Signs & VB & Yes, No \\
\hline
\end{tabular}

3) Formalization: For this stage of the methodology, having already identified the target variable and the observation variable in the previous step, was proceed to build the chosen graphical model, which is the "Bayesian network" as shown in Fig. 5. this model is developed according to the symptoms identified in the previous section. At this stage, by using the Bayesian network graphical model, knowledge base presentation created, for this we identify the rules of inference that will be used for the construction of the knowledge base through logic programming, it should be noted that this stage of the methodology is important because it establishes the rules of inference that are used for the solution of the problem posed, the criteria for the development of the rules of inference is observed in Table III and to culminate in this stage is the one that establishes everything necessary for the implementation stage of the expert system in prolog.

Rules of inference

- Ruler 1 YES (Walk and YES SP1 and No AL and No FU and No CO) THEN TN-V

- Ruler 2 YES (Walk and YES SP1 and YES AL and No FU and No CO) THEN TN-V

- Ruler 3 YES (Walk and YES SP1 and No AL and YES FU and No CO) THEN TN-V

- Ruler 4 YES (Walk and YES SP1 and No AL and no FU and YES CO) THEN TN-V

- Ruler 5 YES (Walk and YES SP1 and YES AL and YES FU and No CO) THEN TN-V

- Ruler 6 YES (Walk and YES SP1 and YES AL and No FU and YES CO) THEN TN-V

- Ruler 7 YES (Walk and YES SP1 and No AL and YES FU and YES CO) THEN TN-V

- Ruler 8 YES (Walk and YES SP1 and YES AL and YES FU and YES CO) THEN TN-V

- Ruler 9 YES (Walk and No SP1 and No AL and No FU and No CO) THEN TN-V

- Ruler 10 YES (Walk and No SP1 and YES AL and No FU and No CO) THEN TN-V

- Ruler 11 YES (Walk and No SP1 and No AL and YES FU and No CO) THEN TN-V

- Ruler 12 YES (Walk and No SP1 and No AL and no FU and SI CO) THEN TN-V

- Ruler 13 YES (Walk and No SP1 and YES AL and YES FU and No CO) THEN TN-V

- Ruler 14 YES (Walk and No SP1 and YES AL and No FU and YES CO) THEN TN-V

- Ruler 15 YES (Walk and No SP1 and No AL and YES FU and YES CO) THEN TN-V

- Ruler 16 YES (Walk and No SP1 and YES AL and YES FU and YES CO) THEN TN-V

- Ruler 17 No (Walk and YES HA and YES SP1 and No FI and No DM and No HI) THEN TN-IV

- Ruler 18 No (Walk and YES HA and YES SP1 and YES FI and No DM and No HI) THEN TN-IV

- Ruler 19 No (Walk and YES HA and YES SP1 and No FI and YES DM and No HI) THEN TN-IV

- Ruler 20 No (Walk and YES HA and YES SP1 and No FI and No DM and YES HI) THEN TN-IV

\section{RESUlt AND Discussion}

1) Implementation: In this step of the methodology chose to develop the Prolog expert system that gives us the tools for logic programming, this system was connected to a web environment interface that will be implemented in netbeans and will be supported by a SQL database. As step I the specifications of the use case of the system were defined. 


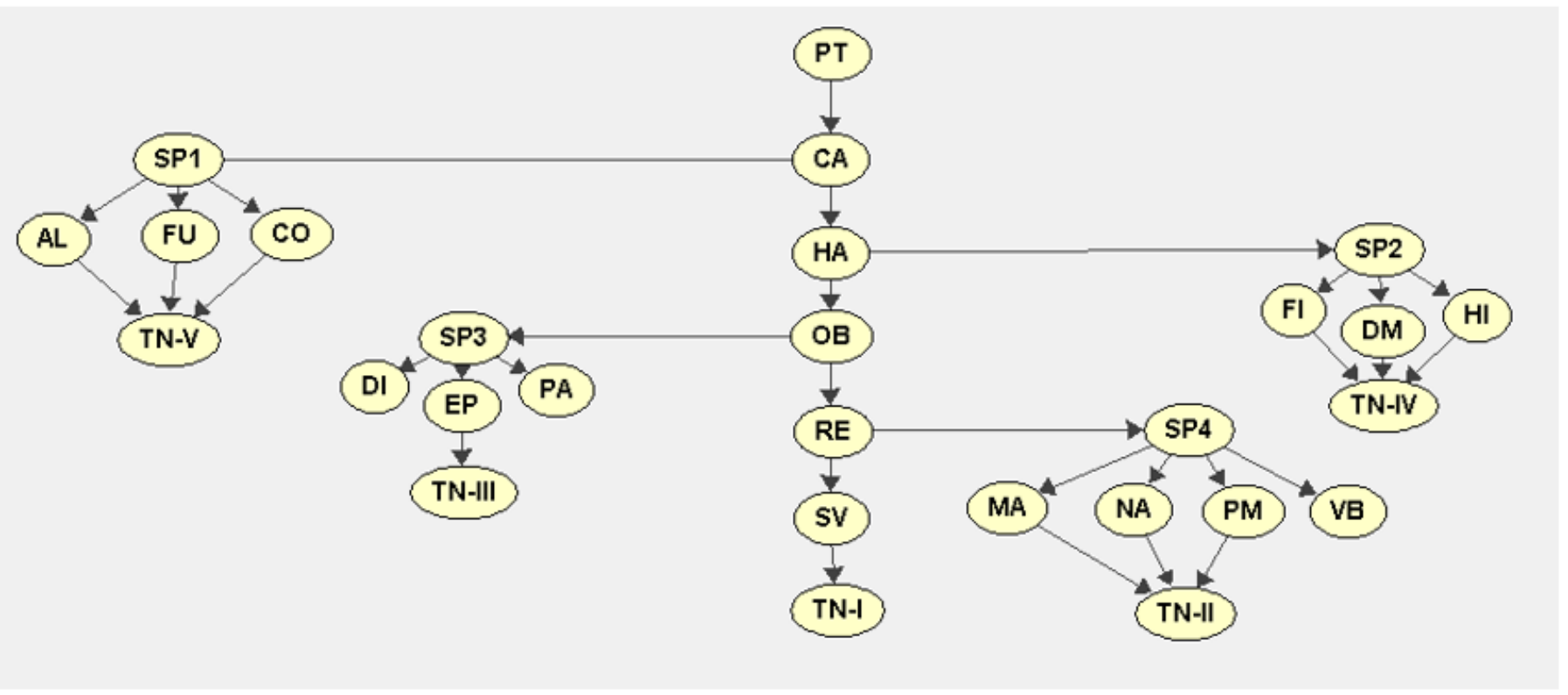

Fig. 5. Knowledge base: Graphical Model Bayesian Network.

TABLE III. RULES OF INFERENCE

\begin{tabular}{|l|l|l|l|l|l|l|l|}
\hline Rule & Age & Weight & $\begin{array}{l}\text { Commom } \\
\text { diseases }\end{array}$ & Cholesterol & Hypertension & $\begin{array}{l}\text { Memory } \\
\text { loss }\end{array}$ & Diagnosis \\
\hline Rule1 & MA & Yes & Yes & Yes & No & Yes & TN-I \\
\hline Rule2 & ME & Yes & Yes & Yes & No & Yes & TN-I \\
\hline Rule3 & ME & Yes & Yes & Yes & No & No & TN-I \\
\hline Rule4 & MA & Yes & Yes & Yes & No & No & TN-I \\
\hline Rule5 & ME & Yes & Yes & Yes & Yes & No & TN-I \\
\hline Rule6 & MA & Yes & Yes & Yes & Yes & No & TN-II \\
\hline Rule7 & ME & Yes & Yes & Yes & Yes & Yes & TN-II \\
\hline Rule8 & MA & Yes & Yes & Yes & Yes & Yes & TN-II \\
\hline Rule9 & MA & Yes & Yes & Yes & Yes & No & TN-II \\
\hline Rule10 & ME & No & Yes & No & Yes & No & TN-III \\
\hline Rule11 & MA & No & No & No & No & Yes & TN-III \\
\hline Rule12 & ME & No & No & Yes & No & No & TN-III \\
\hline Rule13 & MA & No & No & Yes & Yes & Yes & TN-III \\
\hline Rule14 & ME & No & No & Yes & Yes & No & TN-IV \\
\hline Rule15 & MA & No & No & No & Yes & Yes & TN-IV \\
\hline Rule16 & ME & No & No & No & Yes & Yes & TN-IV \\
\hline Rule17 & MA & No & No & No & Yes & Yes & TN-IV \\
\hline Rule18 & ME & No & No & No & No & Yes & TN-V \\
\hline Rule19 & MA & No & No & No & No & Yes & TN-V \\
\hline Rule20 & ME & No & No & No & No & No & TN-V \\
\hline
\end{tabular}

- Patient registration use case: This use case is going to allow registering patients in the database, a procedure that was performed to obtain a better diagnosis from the expert system, this can be seen in Table IV.

- Search patient use case: This use case allows the user to be able to search for patients registered in the system, as shown in Table V.

- Add triage variable use case: Use case that allows the user to add new variables for the triage process, as shown in Table VI.

- Register symptom use case: Use case that allows the user to register new symptoms that are the knowledge base for the expert system, as shown in Table VII.

- Search symptom use case: Use case that allows the
TABle IV. Use Case Module Register Patient

\begin{tabular}{|c|c|c|}
\hline Use Case & \multirow{2}{*}{\multicolumn{2}{|c|}{ Register Pautient }} \\
\hline Code & & \\
\hline Target & \multicolumn{2}{|r|}{$\begin{array}{l}\text { Allow to register new patients in the database, in order } \\
\text { to obtain a better diagnosis from the expert system. }\end{array}$} \\
\hline Preconditions & \multicolumn{2}{|r|}{$\begin{array}{l}\text { The user must be logged in. The user must have per- } \\
\text { mission to access this module. }\end{array}$} \\
\hline Post conditions & \multicolumn{2}{|r|}{ The patient's data is recorded. } \\
\hline Actors & \multicolumn{2}{|c|}{ User } \\
\hline \multirow[t]{6}{*}{ Main Flow } & 1. & User logs in to the system. \\
\hline & & The user accesses the patient module. \\
\hline & 3. & The user presses the add button of the patient module. \\
\hline & 4. & The system displays the form to register the patient. \\
\hline & & $\begin{array}{l}\text { The user enters the patient's DNI, surname and first } \\
\text { name, sex, age, date of birth and then clicks on the } \\
\text { add button. }\end{array}$ \\
\hline & 6. & The system stores the patient. \\
\hline Performance & \multicolumn{2}{|c|}{ High. } \\
\hline Frequency & \multicolumn{2}{|c|}{ Infrequent. } \\
\hline Priority & \multicolumn{2}{|c|}{ High. } \\
\hline
\end{tabular}

user to search and list the symptoms registered in the system, with their respective characteristics, as shown in Table VIII.

- Use case obtain diagnosis: Use case that allows the user to carry out the process of diagnosing the patient, this is done by selecting the symptoms presented by the patient, as shown in Table IX.

- Consult diagnosis use case: Use case that allows the user to consult the patient's diagnosis together with a possible treatment, as shown in Table X.

This database was created in order to store the data obtained from the patient's admission as well as the results obtained from each patient's consultation to the expert system, thus expanding the knowledge base, it contains the following tables with which the database diagram shown in Fig. 6 was generated.

- $\quad$ Patient Table. 


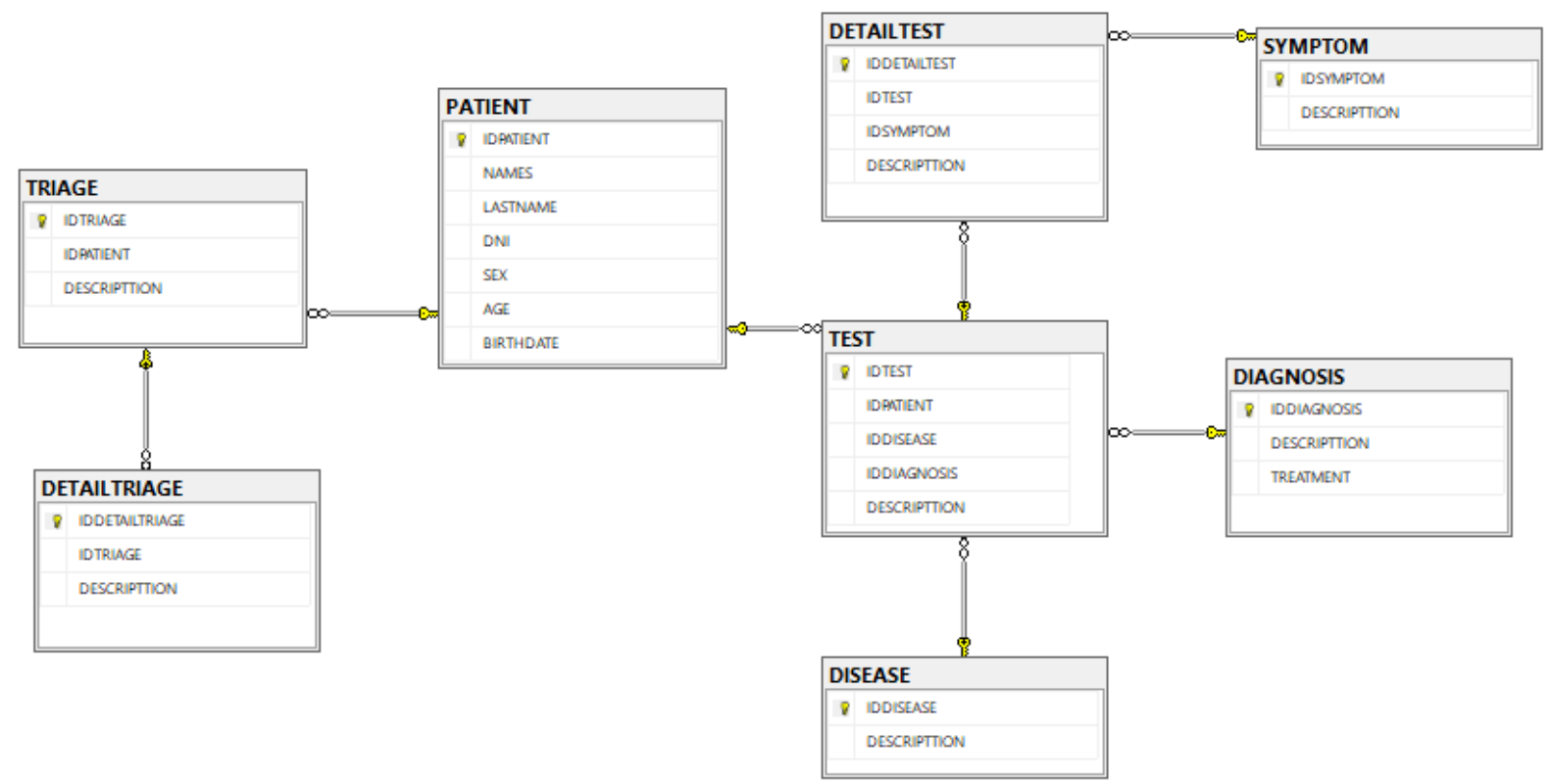

Fig. 6. Expert System Database.

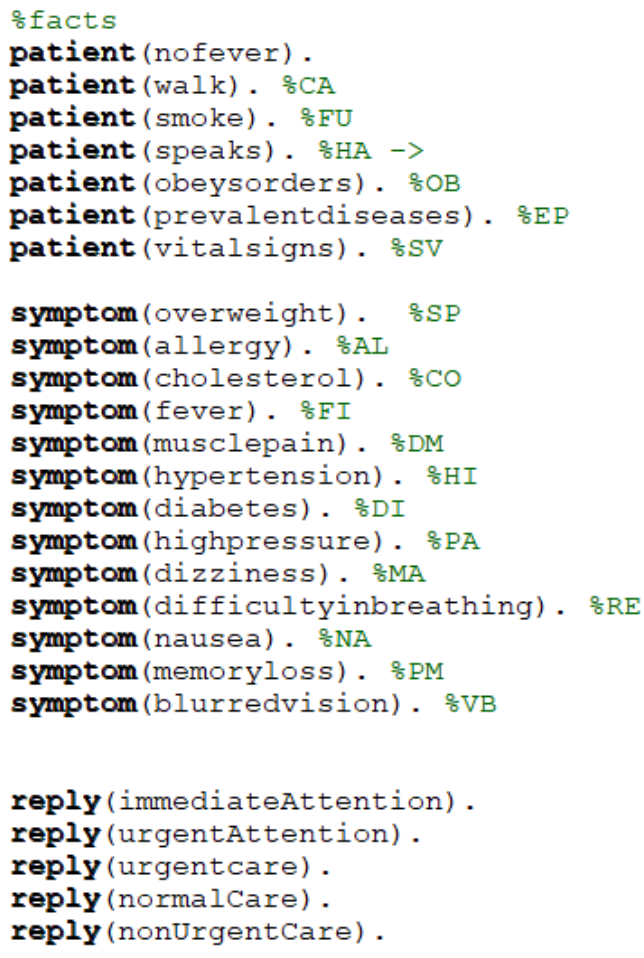

Fig. 7. Statement of Facts. 
TABLE V. Use CASE SEARCh For PATIENT

\begin{tabular}{|c|c|}
\hline Use Case & Patient Search \\
\hline Code & CU02 \\
\hline Target & $\begin{array}{l}\text { Allow the user to search, consult patients registered in } \\
\text { the system. }\end{array}$ \\
\hline Preconditions & $\begin{array}{l}\text { The user must be logged in. The user must have per- } \\
\text { mission to access this module. }\end{array}$ \\
\hline Post conditions & Patient data is displayed. \\
\hline Actors & User \\
\hline \multirow[t]{4}{*}{ Main Flow } & User logs in to the system. \\
\hline & The user accesses the patient module. \\
\hline & $\begin{array}{l}\text { The user clicks on the search button and enters the } \\
\text { DNI of the patient to search for. }\end{array}$ \\
\hline & The system displays the form to register the patient. \\
\hline Performance & High. \\
\hline Frequency & Infrequent. \\
\hline Priority & High. \\
\hline
\end{tabular}

TABLE VI. Use CASe Add Triage Variable

\begin{tabular}{|c|c|}
\hline Use Case & Add triage variables \\
\hline Code & CU03 \\
\hline Target & Allow user to add variables for the triage process. \\
\hline Preconditions & $\begin{array}{l}\text { The user must be logged in. The user must have per- } \\
\text { mission to access this module. }\end{array}$ \\
\hline Post conditions & Data was saved correctly. \\
\hline Actors & User \\
\hline \multirow{5}{*}{ Main Flow } & User logs in to the system. \\
\hline & $\begin{array}{l}\text { The user accesses the triage module and presses the } \\
\text { add button. }\end{array}$ \\
\hline & \begin{tabular}{c|c}
3. & The system displays a form to add more triage \\
variables.
\end{tabular} \\
\hline & The user fills in the data and clicks on save. \\
\hline & The system stores the information. \\
\hline Performance & High. \\
\hline Frequency & Infrequent. \\
\hline Priority & High. \\
\hline
\end{tabular}

TABLE VII. Use CASE REgISTER SyMPtom

\begin{tabular}{|c|c|c|}
\hline Use Case & & Record symptom \\
\hline Code & \multicolumn{2}{|r|}{ 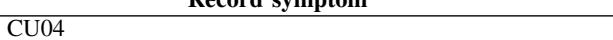 } \\
\hline Target & \multicolumn{2}{|r|}{ Allow user to register new symptoms (knowledge base). } \\
\hline Preconditions & \multicolumn{2}{|r|}{$\begin{array}{l}\text { The user must be logged in. The user must have per- } \\
\text { mission to access this module. }\end{array}$} \\
\hline Post conditions & \multicolumn{2}{|r|}{ The symptom is recorded. } \\
\hline Actors & \multicolumn{2}{|c|}{ User } \\
\hline \multirow[t]{4}{*}{ Main Flow } & 1. & The user accesses the symptoms module. \\
\hline & 2. & The user clicks on the add new symptom button. \\
\hline & & $\begin{array}{l}\text { The user enters the symptom code, name, description, } \\
\text { then clicks the add button. }\end{array}$ \\
\hline & 4. & The symptom is saved in the system. \\
\hline Performance & \multicolumn{2}{|c|}{ High. } \\
\hline Frequency & \multicolumn{2}{|c|}{ Infrequent. } \\
\hline Priority & \multicolumn{2}{|c|}{ High. } \\
\hline
\end{tabular}

TABLE VIII. USE CASE SEARCH FOR SyMPTOM

\begin{tabular}{|c|c|}
\hline Use Case & Record symptom \\
\hline Code & CU05 \\
\hline Target & $\begin{array}{l}\text { Allow the user to search for the symptoms registered } \\
\text { in the system. }\end{array}$ \\
\hline Preconditions & $\begin{array}{l}\text { The user must be logged in.The user must have per- } \\
\text { mission to access this module. }\end{array}$ \\
\hline Post conditions & The searched symptom is displayed in a table. \\
\hline Actors & User \\
\hline \multirow[t]{3}{*}{ Main Flow } & The user accesses the symptoms module. \\
\hline & $\begin{array}{l}\text { The user clicks on the search symptom button and } \\
\text { enters the symptom to search for. }\end{array}$ \\
\hline & $\begin{array}{l}\text { The system displays a table with the searched } \\
\text { symptom and its respective characteristics. }\end{array}$ \\
\hline Performance & High. \\
\hline Frequency & Infrequent. \\
\hline Priority & High. \\
\hline
\end{tabular}

TABle IX. Use Case Get Diagnostic

\begin{tabular}{|c|c|c|}
\hline Use Case & \multirow{2}{*}{\multicolumn{2}{|c|}{ UDtain diagnosis }} \\
\hline Code & & \\
\hline Target & \multicolumn{2}{|c|}{$\begin{array}{l}\text { Allow the user to make the diagnosis to the patient, by } \\
\text { means of the choices of the symptoms presented by the } \\
\text { patient. }\end{array}$} \\
\hline Preconditions & \multicolumn{2}{|r|}{$\begin{array}{l}\text { The user must be logged in.The user must have per- } \\
\text { mission to access this module. }\end{array}$} \\
\hline Post conditions & \multicolumn{2}{|r|}{ Not applicable. } \\
\hline Actors & \multicolumn{2}{|c|}{ User, system. } \\
\hline \multirow[t]{6}{*}{ Main Flow } & & The user enters the diagnostic module. \\
\hline & & The user clicks on the test button. \\
\hline & & $\begin{array}{l}\text { The system redirects to a page where the patient } \\
\text { triage process is performed first. }\end{array}$ \\
\hline & 4. & $\begin{array}{c}\text { The system initiates the diagnostic process by means } \\
\text { of a test. }\end{array}$ \\
\hline & 5. & The user enters the patient's symptoms. \\
\hline & & The system displays the results of the diagnosis. \\
\hline Performance & \multicolumn{2}{|r|}{ (20 } \\
\hline Frequency & \multicolumn{2}{|c|}{ Infrequent. } \\
\hline Priority & \multicolumn{2}{|c|}{ High. } \\
\hline
\end{tabular}

TABle X. Use Case Consult Diagnostics

\begin{tabular}{|c|c|c|}
\hline Use Case & & Consult diagnosis \\
\hline Code & \multicolumn{2}{|c|}{ CU07 } \\
\hline Target & \multicolumn{2}{|c|}{$\begin{array}{l}\text { Allow the user to query the patient's diagnosis by } \\
\text { displaying a treatment. }\end{array}$} \\
\hline Preconditions & \multicolumn{2}{|r|}{ Perform CU10. } \\
\hline Post conditions & \multicolumn{2}{|c|}{ Not applicable. } \\
\hline Actors & \multicolumn{2}{|c|}{ User } \\
\hline \multirow[t]{3}{*}{ Main Flow } & 1. & The user enters the diagnostic module. \\
\hline & & $\begin{array}{l}\text { The user clicks on the search button and enters the } \\
\text { patient's ID number. }\end{array}$ \\
\hline & 3. & $\begin{array}{l}\text { The system displays the results of the diagnosis } \\
\text { performed, providing a possible treatment. }\end{array}$ \\
\hline Performance & \multicolumn{2}{|r|}{1} \\
\hline Frequency & \multicolumn{2}{|c|}{ Infrequent. } \\
\hline Priority & \multicolumn{2}{|c|}{ High. } \\
\hline
\end{tabular}

- $\quad$ Triage table.

- Table Triage detail.

- Symptom table.

- Diagnostic table.

- $\quad$ Test Table.

- Table DetailsTest.

- Disease table.

2) Test: In this stage of the methodology the expert system developed in prolog was tested based on the rules established in the Bayesian network, starting with the statement of facts as shown in Fig. 7 where the first step was to enter the possible symptoms that a patient may have for the triage process, as well as the symptoms that the expert system will handle for this stage of the development process, this part is very important because they are the statements regarding the knowledge base, then the rules were typed as shown in Fig. 8. The rules are the knowledge representation of the expert system that is expressed in natural language and through a conditional, in this case to determine a diagnosis the rules evaluate the symptoms of the knowledge base together with the symptoms that the patient is going to perform and compares them with a priority of attention, which allowed to obtain a good diagnosis. Subsequently, the web application interface was developed, which can be seen in Fig. 9. In order to make the system 


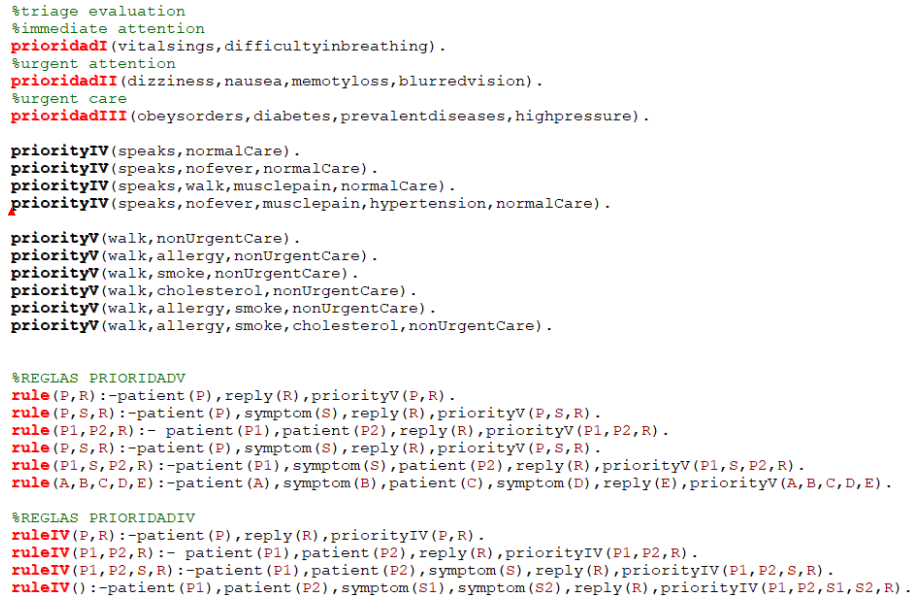

Fig. 8. Expert System Rules.

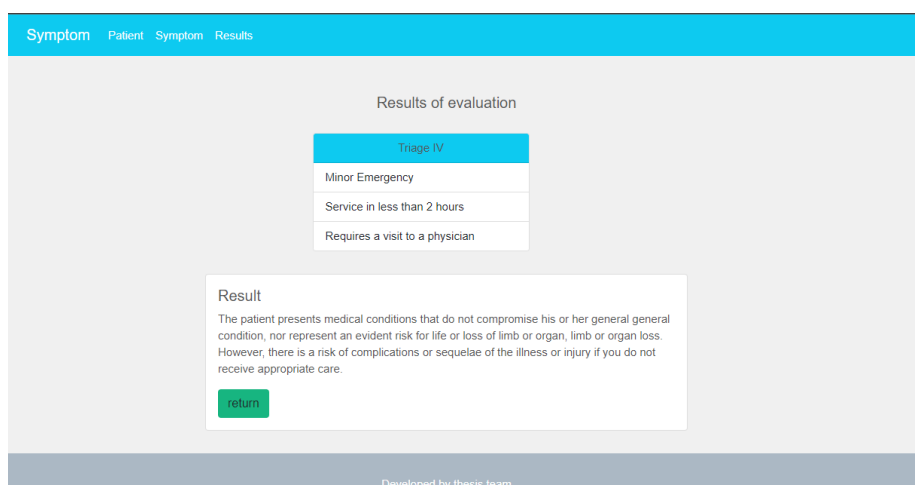

Fig. 9. Test Result.

usable, intuitive and generate a comfortable experience for the user, this interface displays the results obtained from the expert system.

3) Symptom Comparisons on the Web: The results in terms of internet search show interesting data such as for example that the words in terms of search for symptoms related to COVID-19, such as fever, dry cough, sore throat, are the most searched on the web to corporation of other diseases or symptoms such as could be allergy or any other, in Fig. 10. shows the trend of internet search with respect to some symptoms, in this graph you can see that among the symptoms or diseases shown, the term COVID-19 has been the most searched during the last 4 months from July to October 2021, it should be noted that these data are only from searches made in Peru, these data are important to know because they indicate that there is a high trend with respect to queries on the web related to health issues.

\section{CONCLUSION AND FUtURE WORK}

As a final part of this research, it is concluded that there is a perpetual need for digital improvement in healthcare, people will only be able to change their way of thinking by obtaining truthful sources of diagnosis, when they are presented quickly.

The implemented system is a good short term solution that helps to put an end to the problem of the lack of information

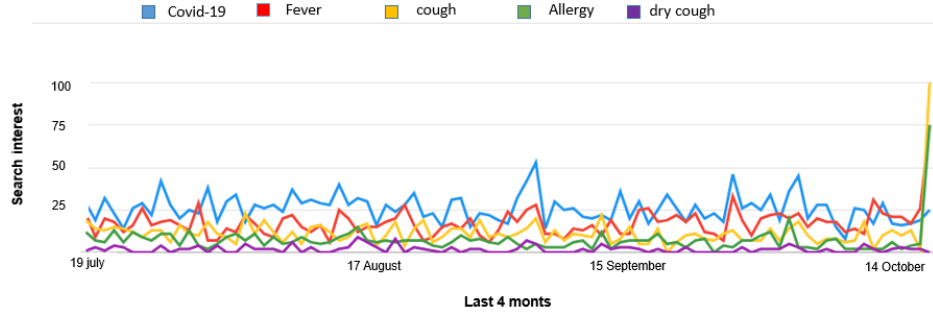

Fig. 10. Comparative Symptom Search.

sources and successfully benefits all types of users, both those who want to search for diagnoses and appointments on the web, as well as those who want to offer their health services, both hospitals and clinics.

For future work, we recommend analyzing well the sequence pattern that needs to be regulated, the logical aspect is one of the most representative parts of the expert system, the rules must comply with a specific and well-structured order. It is recommended to continue with the investigation applying other types of machine learning algorithms.

\section{ACKNOWLEDGMENT}

To thank the support of the University of Sciences and Humanities, through its research institute for the support.

\section{REFERENCES}

[1] J. J. E. MacRohon and J. H. Jeng, "A Real-Time COVID-19 Data Visualization and Information Repository in the Philippines," 2021 9th International Conference on Information and Education Technology, ICIET 2021, pp. 443-447, 2021.

[2] J. Rai, R. C. Tripathi, and N. Gulati, "A comprehensive survey of IT sectors affected by covid-19," Proceedings of the 2020 9th International Conference on System Modeling and Advancement in Research Trends, SMART 2020, pp. 52-54, 2020.

[3] S. Ayani, F. Sadoughi, R. Jabari, K. Moulaei, and H. Ashrafi-Rizi, "Evaluation Criteria for Health Websites: Critical Review," Frontiers in Health Informatics, vol. 9, no. 1, 2020.

[4] K. József, "Health information on the internet," Orvosi Hetilap, vol. 159, no. 22, pp. 855-862, 2018.

[5] A. J. C. Sotomayor and L. Andrade-Arenas, "Mobile application oriented to the attention of blood donors in the medical centers of northern lima," in 2020 IEEE Engineering International Research Conference (EIRCON). IEEE, 2020, pp. 1-4.

[6] C. Watters, B. Miller, M. Kelly, V. Burnay, Y. Karagama, and E. Chevretton, "Virtual voice clinics in the COVID-19 era: have they been helpful?" European Archives of Oto-Rhino-Laryngology, vol. 278, no. 10, pp. 4113-4118, 2021. [Online]. Available: https://doi.org/10.1007/s00405-021-06643-6

[7] S. A. H. Morales, M. F. M. Antayhua, and L. Andrade-Arenas, "Development of predictions through machine learning for sars-cov-2 forecasting in peru," International Journal of Advanced Computer Science and Applications, vol. 12, no. 11, 2021. [Online]. Available: http://dx.doi.org/10.14569/IJACSA.2021.0121188

[8] J. J. Kim and G. A. Bekey, "Adaptive abstraction in expert systems for medical diagnosis," Proceedings - IEEE Symposium on Computer-Based Medical Systems, vol. 1992-June, pp. 345-352, 1992.

[9] J. Muhammad, "Web-based Clinic Management System ( CMS )," vol. 8, no. 05, pp. 131-135, 2019.

[10] F. Andrade-Chaico and L. Andrade-Arenas, "Projections on insecurity, unemployment and poverty and their consequences in lima's district san juan de lurigancho in the next 10 years," in 2019 IEEE Sciences and Humanities International Research Conference (SHIRCON), 2019, pp. $1-4$. 
[11] J. Imlawi, "Health website success: User engagement in health-related websites," International Journal of Interactive Mobile Technologies, vol. 11, no. 6, pp. 49-64, 2017.

[12] S. Boon-Itt, "Quality of health websites and their influence on perceived usefulness, trust and intention to use: An analysis from Thailand," Journal of Innovation and Entrepreneurship, vol. 8, no. 1, 2019.

[13] F. Afsana, M. A. Kabir, N. Hassan, and M. Paul, "Automatically Assessing Quality of Online Health Articles," IEEE Journal of Biomedical and Health Informatics, vol. 25, no. 2, pp. 591-601, 2021.

[14] N. E. Youngblood, "Digital inclusiveness of health information websites," Universal Access in the Information Society, vol. 19, no. 1, 2020

[15] M. T. Thielsch, C. Thielsch, and G. Hirschfeld, "How Informative is Informative? Benchmarks and Optimal Cut Points for E-Health Websites," Proceedings of the Mensch und Computer 2019, 2019.

[16] L. Z. Gao, "Study of health education for university students in the new period," Proceedings 2011 International Conference on Human Health and Biomedical Engineering, HHBE 2011, pp. 929-931, 2011.

[17] S. Valizadeh-Haghi, Y. Khazaal, and S. Rahmatizadeh, "Health websites on COVID-19: Are they readable and credible enough to help public self-care?" Journal of the Medical Library Association, vol. 109, no. 1 , 2021.

[18] V. L. Carmen Milagros, "Universidad Nacional Mayor de San Marcos Analysis of the quality and content of web pages in Spanish about their nutritional advice to lose weight To qualify for the Professional Degree of Bachelor of Nutrition," 2020.

[19] E. J. G. Buitrón, D. C. Corrales, J. Avelino, J. A. Iglesias, and J. C. Corrales, "Rule-based expert system for detection of coffee rust warnings in colombian crops," Journal of Intelligent and Fuzzy Systems, vol. 36, no. 5, pp. 4765-4775, 2019.

[20] D. C. Brock, "Learning from artificial intelligence's previous awakenings: The history of expert systems," AI Magazine, vol. 39, no. 3, pp. $3-15,2018$. 